\title{
Adult-onset deletion of Pten increases islet mass and beta cell proliferation in mice
}

\author{
Kai-Ting Yang • Jennifer-Ann Bayan • Ni Zeng • Richa Aggarwal • Lina He • \\ Zhechu Peng • Anketse Kassa • Melissa Kim • Zhiou Luo • Zhenrong Shi • \\ Vivian Medina $\cdot$ Keerthi Boddupally $\cdot$ Bangyan L. Stiles
}

Received: 9 April 2013 / Accepted: 27 September 2013 / Published online: 26 October 2013

(C) Springer-Verlag Berlin Heidelberg 2013

\begin{abstract}
Aims/hypothesis Adult beta cells have a diminished ability to proliferate. Phosphatase and tensin homologue (PTEN) is a lipid phosphatase that antagonises the function of the mitogenic phosphatidylinositol 3-kinase (PI3K) pathway. The objective of this study was to understand the role of PTEN and PI3K signalling in the maintenance of beta cells postnatally. Methods We developed a Pten ${ }^{\text {lox/lox}}$; Rosa26 $6^{\text {lacz }}$; RIP$\mathrm{CreER}^{+}$model that permitted us to induce Pten deletion by treatment with tamoxifen in mature animals. We evaluated islet mass and function as well as beta cell proliferation in 3and 12-month-old mice treated with tamoxifen (Pten deleted) vs mice treated with vehicle (Pten control).

Results Deletion of Pten in juvenile (3-month-old) beta cells significantly induced their proliferation and increased islet mass. The expansion of islet mass occurred concomitantly
\end{abstract}

Kai-Ting Yang and Jennifer-Ann Bayan contributed equally to this study.

Electronic supplementary material The online version of this article (doi:10.1007/s00125-013-3085-8) contains peer-reviewed but unedited supplementary material, which is available to authorised users.

K.-T. Yang $\cdot$ K. Boddupally

Department of Biochemistry and Molecular Biology,

University of Southern California, Los Angeles, CA, USA

J.-A. Bayan $\cdot$ N. Zeng $\cdot$ R. Aggarwal $\cdot$ L. He $\cdot$ Z. Peng $\cdot$ A. Kassa $\cdot$

M. Kim · Z. Luo $\cdot$ Z. Shi $\cdot$ B. L. Stiles $(\triangle)$

Department of Pharmacology and Pharmaceutical Sciences,

School of Pharmacy, University of Southern California,

Los Angeles, CA 90033, USA

e-mail: bstiles@usc.edu

\section{Medina}

System Biology Department, University of Southern California,

Los Angeles, CA, USA

\section{B. L. Stiles}

Department of Pathology, Keck School of Medicine,

University of Southern California, Los Angeles, CA, USA with the enhanced ability of the Pten-deleted mice to maintain euglycaemia in response to streptozotocin treatment. In older mice ( $>12$ months of age), deletion of Pten similarly increased islet mass and beta cell proliferation. This novel finding suggests that PTEN-regulated mechanisms may override the ageonset diminished ability of beta cells to respond to mitogenic stimulation. We also found that proteins regulating G1/S cellcycle transition, such as cyclin D1, cyclin D2, p27 and p16, were altered when PTEN was lost, suggesting that they may play a role in PTEN/PI3K-regulated beta cell proliferation in adult tissue.

Conclusions/interpretation The signals regulated by the PTEN/PI3K pathway are important for postnatal maintenance of beta cells and regulation of their proliferation in adult tissues.

Keywords Adult beta cells $\cdot$ PTEN $\cdot$ Regeneration $\cdot$ RIP-CreER

$\begin{array}{ll}\text { Abbreviation } \\ \text { CON } & \text { Control group } \\ \text { ERK } & \text { Extracellular signal-regulated kinase } \\ \text { EXP } & \text { Experimental group } \\ \text { EZH2 } & \text { Enhancer of zeste homologue 2 } \\ \text { FOXO } & \text { Forkhead box O protein } \\ \text { H\&E } & \text { Hematoxylin and eosin } \\ \text { HGF } & \text { Hepatic growth factor } \\ \text { MAPK } & \text { Mitogen-activated protein kinase } \\ \text { MTOR } & \text { Mammalian target of rapamycin } \\ \text { PDGF } & \text { Platelet-derived growth factor } \\ \text { PI3K } & \text { Phosphatidylinositol 3-kinase } \\ \text { PTEN } & \text { Phosphatase and tensin homologue } \\ \text { RIP } & \text { Rat insulin promoter } \\ \text { STZ } & \text { Streptozotocin } \\ \text { S6K } & \text { S6 protein kinase } \\ \text { TSC 1/2 } & \text { Tuberous sclerosis complex 1/2 }\end{array}$




\section{Introduction}

The mass of pancreatic islets is an important factor in the maintenance of glucose homeostasis. During physiological maintenance, both cell proliferation and apoptosis rates are low in the adult endocrine pancreas [1-3]. During times of metabolic stress and after pancreatic or beta cell injury, the mitotic activity and mass of beta cells both increase $[1,3]$. This ability of beta cells to proliferate in response to stress diminishes with age and becomes limited in aged animals. In humans, no beta cells are 'born' beyond the first 30 years of life [4]. Recent studies using genetically modified animals suggest a major role for the G1/S cell-cycle machinery in the growth of beta cells. Several growth factors have been found to play roles in beta cell function, including insulin, IGF, hepatic growth factor (HGF) and platelet-derived growth factor (PDGF). Mice lacking the HGF receptor suffer from smaller islet mass and enhanced apoptosis $[5,6]$, whereas overexpression of HGF leads to enhanced islet function with increased proliferation $[7,8]$. Similarly, IGF-1 treatment prevents apoptosis and is thought to be mitogenic for beta cell growth [9-11]. Inactivation of cell surface receptors for PDGF has been shown to prevent proliferation of beta cells in neonatal as well as adult stages [12]. Gene targeting studies have shown that phosphatidylinositol 3-kinase (PI3K) and Akt, the downstream signals of IGF-1, insulin, PDGF and HGF, likewise play a mitogenic role in beta cell growth [13-15].

Phosphatase and tensin homologue (PTEN) on chromosome 10 is a lipid phosphatase that antagonises the functions of PI3K and Akt. Heterozygous deletion of Pten was previously demonstrated to rescue the dysfunctional islets in Irs $2^{--}$ mice [16]. Our group and others reported that mice lacking PTEN (Pten ${ }^{\text {loxP/loxP}} ;$ RIP-Cre ${ }^{+}$) specifically in the beta cells have more and larger islets $[17,18]$. We showed that beta cell mitotic activity is significantly increased in the Pten ${ }^{\text {loxP/loxP; }}$; RIP-Cre ${ }^{+}$mice during embryogenesis, and in response to STZ-induced regeneration of beta cells [18]. Using the same model, we recently showed that PTEN loss also prevents the decline in proliferation capacity in aged beta cells and restores the ability of aged beta cells to respond to injury-induced regeneration [19]. In addition, we identified cyclin D1-EZH2-p16 $6^{\mathrm{INK} 4 \mathrm{a}}$ as the signal node that mediates this beta cell proliferation response in the Pten $^{\text {loxP/loxP }} ;$ RIP-Cre ${ }^{+}$model [19]. The $\mathrm{p} 16^{\mathrm{INK} 4 \mathrm{a}}$ signal is also involved in PDGF-induced beta cell growth in aged islets [12], whereas other attempts to induce proliferation in older animals has failed when this signal is not altered [20]. While genetic studies have shown that alterations of enhancer of zeste homologue 2 (EZH2) and associated polycomb proteins can affect proliferation rates much later in life $[3,21,22]$, it is an open question as to whether intervention after onset of maturity can have a similar result. To address this question, we engineered a novel mouse model (Pten ${ }^{\text {loxP/loxP }}$; RIP-CreER ${ }^{+}$) in which Pten can be deleted in beta cells postnatally. This model, for the first time, allowed us to evaluate the effect of activating mitogenic signals specifically in adult beta cells without the complications of developmental effects. We show here that deletion of Pten is capable of inducing the proliferation of beta cells in mice at both 3 and 12 months of age. Analysis of the downstream signalling shows upregulation of $\mathrm{D}$ cyclins and downregulation of cell-cycle inhibitor $\mathrm{p} 27$ and $\mathrm{p} 16^{\mathrm{INK} 4 \mathrm{a}}$, suggesting a role for these $\mathrm{G} 1 / \mathrm{S}$ transition machinery proteins in the adult maintenance of beta cell mass by PTEN/PI3K signalling.

\section{Methods}

Animals Targeted deletion of Pten in beta cells was achieved by crossing Pten ${ }^{\text {loxP/loxp }}$ mice with rat insulin promoter$\mathrm{CreER}^{+}$(RIP-CreER ${ }^{+}$) mice [23]. These mice were also crossed with $R o s a^{\text {lacZ/lacZ }}$ reporter mice to generate Pten ${ }^{\text {loxP/loxP }}$; Rosa26 ${ }^{\text {lacZ }}$; RIP-CreER mice. We show here that a total of $30 \mathrm{mg}$ tamoxifen delivery (five doses of $6 \mathrm{mg}$ ) is sufficient to allow a majority of the cells that express insulin (beta cells) to be labelled with $\beta$-gal, indicating that $\mathrm{Cre}$ recombinase is sufficiently expressed in these cells (electronic supplementary material [ESM] Fig. 1a). We used male $P_{\text {ten }}^{\text {loxP/loxP }}$; Rosa26 $6^{\text {lacZ/lacZ; RIP-CreER }}{ }^{+}$mice (with tamoxifen) as our experimental group (Pten null, EXP) and $P_{\text {ten }}^{\text {loxP/loxP }}$; Rosa26 $6^{\text {lacZ/lacZ; }}$ RIP-CreER ${ }^{-}$(with tamoxifen) or Pten ${ }^{\text {loxP/loxP }}$ and Rosa26 $6^{\text {lacZ/lacZ; RIP-CreER }}{ }^{+}$mice (with corn oil) as our controls (CON). Compared with CON mice, tamoxifen treatment in Pten ${ }^{\text {loxP/loxP }}$; Rosa lacZ/lacZ; RIP-CreER ${ }^{+}$mice (EXP) was the only one showing expression of $R o s a^{\text {lacZ }}$ in the islets, as indicated by the blue staining. This result suggests that Cre recombinase is active in the islets of EXP mice and inactive in the three CON groups. Minimum staining was observed in the exocrine pancreas, indicating specificity of the Cre expression and thus Pten deletion specifically in the islets. Mice were housed in a temperature-, humidity- and light-controlled room (12 h light/dark cycle), and were allowed free access to food and water. All experiments were conducted according to the Institutional Animal Care and Use Committee of the University of Southern California research guidelines.

Tamoxifen injection Tamoxifen (Sigma-Aldrich, St Louis, MO, USA) was prepared in corn oil at a concentration of $20 \mathrm{mg} / \mathrm{ml}$. Mice were given an i.p. injection of either corn oil (vehicle) as control or tamoxifen (a dose of $6 \mathrm{mg}$ every 3 days for five doses; $30 \mathrm{mg}$ total) and then killed and dissected after 1 month to evaluate the effectiveness of the injection on inducing Pten deletion or at indicated time points for analysis of beta cell proliferation and phenotypes. 
In situ $X$-gal staining Fresh pancreatic tissues were rinsed with a mild detergent used to enhance the permeability of the tissue. Tissues were then fixed with $\mathrm{Zn}$-Formalin (containing $0.1 \% \mathrm{ZnSO}_{4}$ and $4 \%$ formaldehyde; Sigma-Aldrich) for $1 \mathrm{~h}$ and stained with $1 \mathrm{mg} / \mathrm{ml} \mathrm{X}$-gal (Sigma-Aldrich). The following day, tissues were rinsed with $\mathrm{PBS}+3 \% \mathrm{DMSO}$ and paraffin-embedded for sectioning. Sections were counterstained with haematoxylin and eosin (H\&E).

Plasma assays Glucose levels were determined using a commercially available Therasense glucometer from tail-vein puncture blood sampling. Fasting glucose was determined from overnight-fasted mice. For glucose tolerance testing, glucose ( $2 \mathrm{mg} / \mathrm{kg}$ body weight) was injected intraperitoneally and plasma glucose evaluated at indicated time points after the injection. Blood samples were also obtained through orbital eye bleeding or cardiac puncture for analysis of plasma insulin levels. Plasma was separated from the blood samples and used for insulin determination with an insulin Elisa kit (Alpco, Salem, NH, USA).

Relative islet area determination Pancreatic tissue was fixed overnight in $\mathrm{Zn}$-Formalin (10\%) solution containing $1 \% \mathrm{Zn}$ sulfate, embedded in paraffin and sectioned into $4 \mu \mathrm{m}$ slices. H\&E staining was performed for morphological analysis. Islet and pancreas area was measured using the Axiovision 4.5 software (Zeiss, Thornwood, NY, USA). Islet and pancreas areas were measured from three sections per mouse, $60 \mu \mathrm{m}$ and $200 \mu \mathrm{m}$ apart, for quantitative analysis. The islet-topancreas ratio was calculated and graphed.

Determination of cell proliferation $\mathrm{BrdU}(1 \mathrm{mg} / \mathrm{ml}$; SigmaAldrich) was administered in the drinking water for five consecutive days. Cell proliferation was then evaluated with immunohistochemical analysis using anti-BrdU antibody and reported as total \% BrdU-positive beta cells. Sections were costained with insulin or $\beta$-gal to visualise islets and beta cells. For quantitative analysis, BrdU-positive cells were counted from five mice. Three sections per mouse, 60 and $200 \mu \mathrm{m}$ apart, were used for quantitative analysis. All insulin- or $\beta$-galpositive cells from the three slides were counted. The mitotic index was determined using the percentage of BrdU + insulinor $\beta$-gal-positive cells vs total insulin/ $\beta$-gal positive cells.

Streptozotocin treatment Male mice from the 3-month-old cohort were injected intraperitoneally with streptozotocin (STZ) $(50 \mathrm{mg} / \mathrm{kg}$ body weight; Sigma-Aldrich) daily for five consecutive days. Following BrdU pulse-labelling (5 days in drinking water), mice were killed for tissue collection and assessed for beta cell proliferation and apoptosis.

Determination of cell apoptosis Beta cell apoptosis was evaluated using TUNEL. Paraffin-embedded slides were stained and examined using the TUNEL assay kit (Roche, Indianapolis, IN, USA).

Immunohistochemistry Immunohistochemistry and indirect immunofluorescence was performed as previously described [18] using the following antibodies: PTEN (Cell Signaling, Danvers, MA, USA); insulin (Invitrogen, Carlsbad, CA, USA); BrdU (BD Pharmingen, San Jose, CA, USA), $\beta$-galactosidase, cyclin D1, cyclin D2, p16 and p27 (Santa Cruz, Santa Cruz, CA, USA).

Western immunoblotting Islets were handpicked and lysed by tissue extraction buffer (Invitrogen). Lysates with equal amounts of protein were resolved by SDS-PAGE, followed by transferring to polyvinylidene fluoride membrane for immunoblotting. The membranes were probed with specific antibodies against cyclin D1, cyclin D2, p27, EZH2 and p16 (Santa Cruz) and anti- $\beta$-actin (Sigma-Aldrich).

Statistics Student's $t$ tests were performed to compare the differences between control and Pten null mice on quantified data. Data are presented as mean \pm SEM. Statistical analysis was calculated by a one-way ANOVA with Bonferroni correction as a post-hoc test for comparing the differences between groups on quantified data.

\section{Results}

Generation of Pten ${ }^{\text {loxP/loxP }}$; Rosa $a^{\text {lacz/lacZ }}$; RIP-CreER mice Genomic PCR analysis of DNA isolated from islets of CON vs EXP mice demonstrated that tamoxifen treatment induced deletion of Pten in Pten ${ }^{\text {loxP/loxP }} ;$ Rosa $a^{\text {lacZ/lacZ; }}$ RIP-CreER ${ }^{+}$mice as indicated by the appearance of the $\Delta 5$ band, while no Pten deletion was observed in vehicletreated mice (ESM Fig. 1b). Analysis of protein isolated from mouse islets confirmed deletion of Pten in the EXP group compared with the CON group, as shown by the significant reduction in PTEN protein expression in the EXP group (ESM Fig. 1b). As a result, the phosphorylated form of Akt, a target of PI3K/PTEN regulation, was increased in the same islets. We further confirmed that PTEN was lost from islet beta cells using indirect immunofluorescence (ESM Fig. 1c). In control islets, PTEN staining was observed in the nucleus of the beta cells, as reported $[18,24]$. This nuclear staining was lacking in most of the islets from the EXP mice.

Deletion of Pten post-embryonic development did not affect the body weight or pancreas weight of the EXP mice (ESM Fig. 2). Partial deletion of Pten in the hypothalamus of the $\mathrm{Pten}^{\text {loxP/loxP }}$; RIP-Cre ${ }^{+}$mice has been attributed to be the cause of the smaller body size [17]. Analysis of DNA isolated from brain tissue of the EXP mice showed no deletion of Pten ( $\Delta 5$ band) (ESM Fig. 1b). We also found no difference in 
PTEN protein expression in brain tissue lysates from the CON and EXP groups (ESM Fig. 1b). Immunostaining of brain sections demonstrated minimum expression of $\beta$-gal after Cre recombination events (ESM Fig. 1d). Thus, the Pten ${ }^{\text {loxP/loxP; }}$ Rosa ${ }^{\text {lacZ/lacZ}}$; RIP-CreER ${ }^{+}$model can be used for evaluating the effect of PTEN loss on beta cell proliferation in adult pancreas.

Deletion of Pten in both juvenile and adult pancreas results in increased islet mass We deleted Pten from 3-month-old juvenile mouse beta cells and then killed the mice at various time points to evaluate the effects of Pten deletion on islet mass and function (Fig. 1a). Group 1 mice were killed 1 month after the last dose of tamoxifen treatment, Group 2 mice were

a

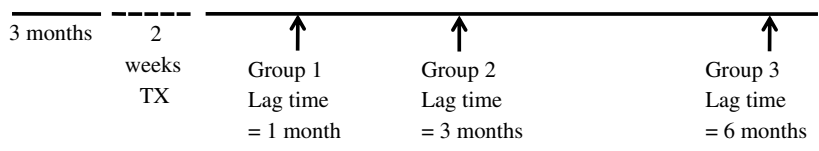

b
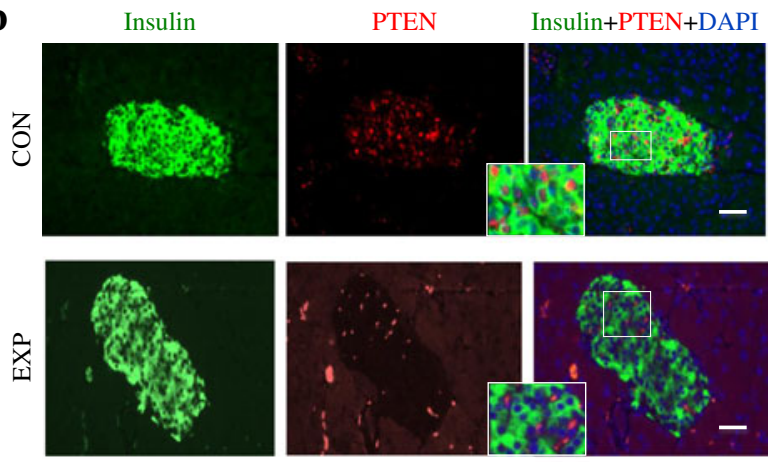

c

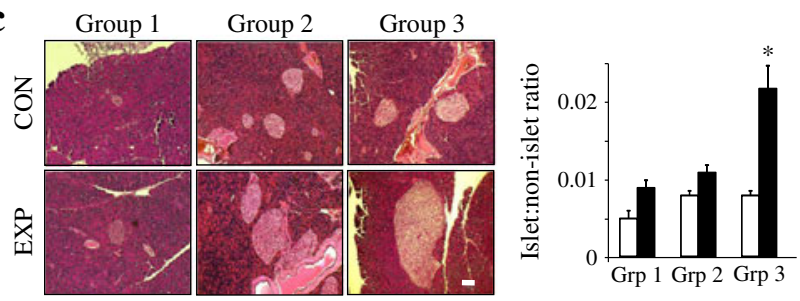

Fig. 1 Deletion of Pten in juvenile mouse beta cells leads to increased relative islet area. (a) Schematic figure of the experimental protocol. At three months of age, mice were treated with tamoxifen (TX, $30 \mathrm{mg}$ total dose) or corn oil (vehicle) and then killed for analysis at 1 month (Group 1), 3 months (Group 2) or 6 months (Group 3) post treatment. Corn oiland tamoxifen-treated $\mathrm{CreER}^{-}$mice and corn oil-treated $\mathrm{CreER}^{+}$mice were controls $(\mathrm{CON})$ whereas tamoxifen-treated $\mathrm{CreER}^{+}$mice were experimental (EXP) mice. (b) Immunofluorescent staining of mouse pancreas sections with insulin (green), PTEN (red) and DAPI (blue). PTEN was expressed in the nucleus of the islet cells from CON and was lacking in the EXP islets. Inset, higher magnification images of boxed areas. (c) Representative image of CON and Pten null (EXP) mouse pancreases stained with $\mathrm{H} \& \mathrm{E}$ for all three time points. Islet to non-islet area ratio was calculated to determine the relative islet area $(n=5$ per genotype, per group). The error bars represent the SEM for all mice analysed for that group. ${ }^{*} p<0.05$, CON (white bars) vs Pten null (EXP, black bars) groups. Scale bars, $50 \mu \mathrm{m}$ killed after 3 months and Group 3 were killed 6 months after treatment (Fig. 1a). Immunofluorescence analysis demonstrates robust $\beta$-gal staining in the islets of all three groups of mice, suggesting that Cre was efficiently active in islets from all three groups (ESM Fig. 3). Immunofluorescence analysis of PTEN in Group 1 mice confirmed loss of PTEN staining in islets of EXP mice (Fig. 1b). We determined the relative islet area by measuring the area of the islets vs pancreas (islet/pancreas ratio). In the $\mathrm{CON}$ mice, this ratio was low in all three groups of mice $(0.005-0.01)$. Deletion of Pten led to an increased islet/pancreas ratio in the EXP mice, particularly in Group 3 in which a significant twofold increase was observed (Fig. 1c).

To determine whether deletion of Pten in 3-month-old beta cells is capable of inducing their mitotic activity, we evaluated the mitotic rate of islet beta cells from all three groups using a BrdU incorporation assay (Fig. 2). Our data demonstrated an increased proliferation rate in islets where Pten was deleted vs islets where Pten was present. A moderate increase (1.2-fold) of BrdU incorporation was observed for beta cells 1 month after tamoxifen injection (Group 1, Fig. 2b). In Groups 2 and 3 , where the lag time was longer, the proliferation rate was two and three times higher in islets lacking PTEN than in control islets, respectively (Fig. 2b).

We also deleted Pten in 12-month-old adult mice (Figs 3 and 4), in which adaptive proliferation is severely restricted in beta cells [1]. Mice were killed after a 1 month (Group 1), 9 month (Group 2) and 12 month lag time (Group 3) following the last tamoxifen injection (Fig. 3a). Similar to the 3-monthold juvenile mice, tamoxifen had no effect on the pancreas weight or body weight of the mice (data not shown). Tamoxifen treatment led to the disappearance of PTEN staining in the beta cells (Fig. 3b). Quantitative analysis showed that all EXP mice had higher islet/pancreas ratio compared with CON mice (Fig. 3c). Similar to the findings in 3-month-old mice, the islet/pancreas ratio was about 1.5- to twofold higher in the EXP groups vs the CON groups. Analysis of the mitotic rate showed that deletion of Pten (EXP) at this age consistently induced the proliferation of beta cells (Fig. 4). BrdU incorporation was increased by approximately two- to threefold in all three EXP vs CON groups (Fig. 4b).

Pten deletion in adult mice does not affect glucose homeostasis We determined the random and fasting glucose and insulin concentrations in the CON and EXP mice 1 month after tamoxifen injection. Our data showed no significant differences in the limited sets of the variables that we determined (Fig. 5). The response of CON and EXP mice to glucose stimulation did not differ significantly either (Fig. 5e, f). The long-term adaptation effects of PTEN inhibition in adult mice and the effects of this adult-onset deletion of Pten on the systemic physiological response of the mice remains to be determined with more detailed analysis. 

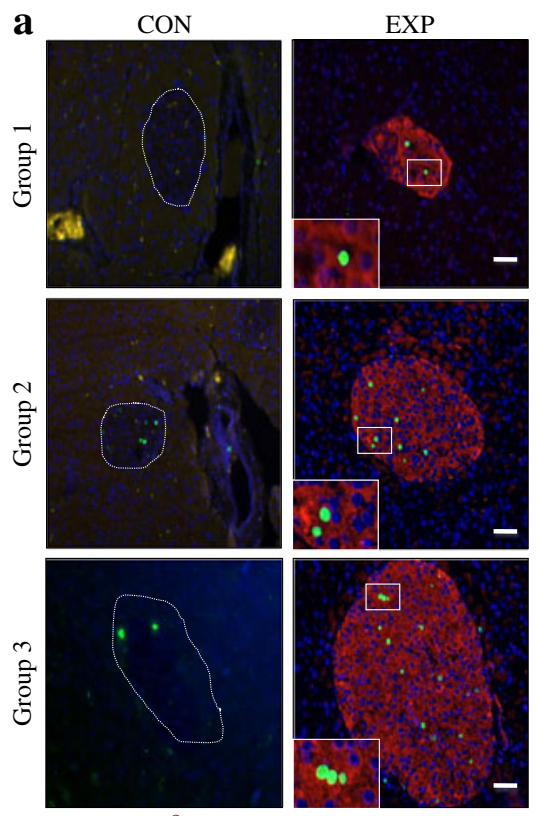

$\beta-\mathrm{Gal}+\mathrm{BrdU}+\mathrm{DAPI}$
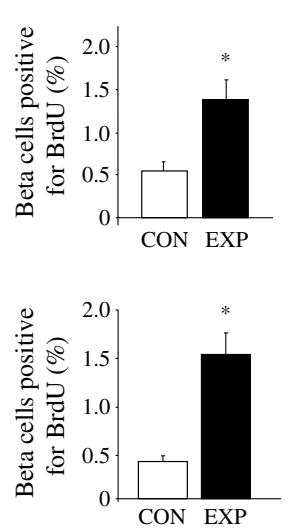

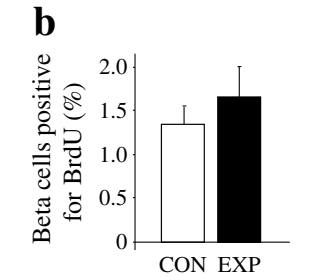

Fig. 2 Deletion of Pten in juvenile mouse beta cells leads to increased cell proliferation. (a) Representative image of pancreas from control $(\mathrm{CON})$ and Pten null (EXP) mice. Sections were analysed for $\beta$-gal (red), BrdU (green) and DAPI (blue) using immunofluorescence. Dashed circles indicate islet area. Inset, higher magnification images of boxed areas. Scale bar, $50 \mu \mathrm{m}$. (b) Quantification of BrdU and $\beta$-gal doublepositive cells. Data are reported as percentage of $\mathrm{BrdU}+\beta$-gal doublepositive vs total $\beta$-gal-positive cells. The bars represent the average percentage of BrdU-positive beta cells in control and Pten null mouse islets. Group 1 was analysed 1 month after the last dose of tamoxifen in 3month-old mice. Groups 2 and 3 were 3 months and 6 months post treatment, respectively ( $n=5$ or 6 per genotype, per group). The error bars represent the SEM for all mice analysed for that group. ${ }^{*} p<0.05$, $\mathrm{CON}$ vs Pten null (EXP) groups

To address the functional consequence of the higher islet/ pancreas ratio observed with adult-onset deletion of Pten, we stressed the 3-month-old cohort of mice by inducing hyperglycaemia using the beta cell toxin STZ. STZ treatment significantly increased plasma glucose levels in the CON mice (approximately 15 vs $5 \mathrm{mmol} / \mathrm{l}$, respectively, in all three groups of mice) (Fig. 6a). In comparison, plasma glucose levels in the STZ-treated Pten null (EXP) mice remained at approximately $5 \mathrm{mmol} / \mathrm{l}$ (Fig. 6a), indicating that the beta cells were functional. Thus, the higher islet area in EXP mice did improve the physiological function of the islets.

We evaluated the proliferation capacity of the beta cells under these stressed conditions. Similar to previous observations [2, 18, 25], STZ treatment led to shrinkage of islets and loss of insulin staining, with few islets retaining insulin staining in $\mathrm{CON}$ mice. A greater percentage of BrdU-positive beta cells was observed in the EXP mice (in which Pten was deleted) than in the CON mice (in which Pten was intact) (Fig. 6b) ( $5 \pm 0.3 \%$ vs $2.5 \pm 0.3 \%, n=3, p=0.0016$ in Group 1$)$. However, in Group 1 mice the majority of this mitotic activity a
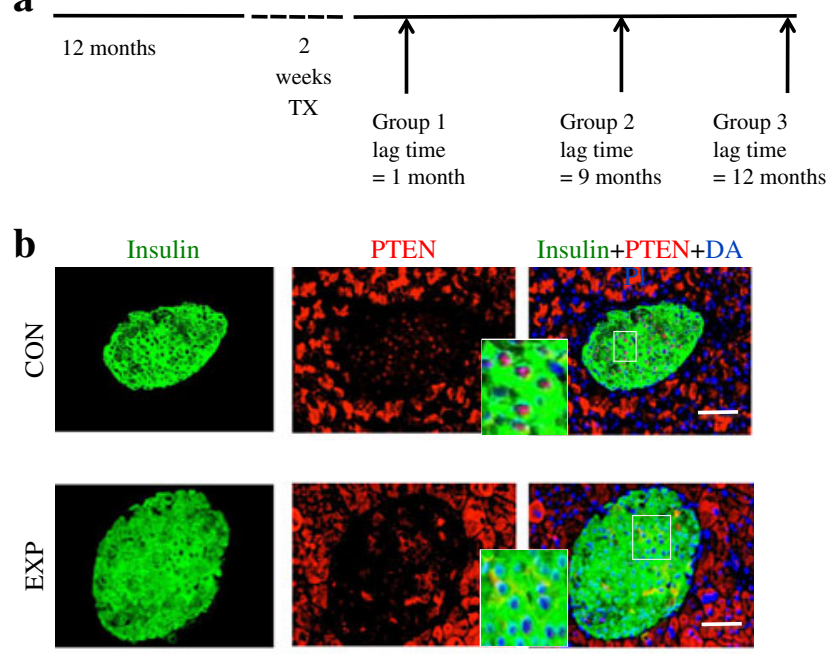

c
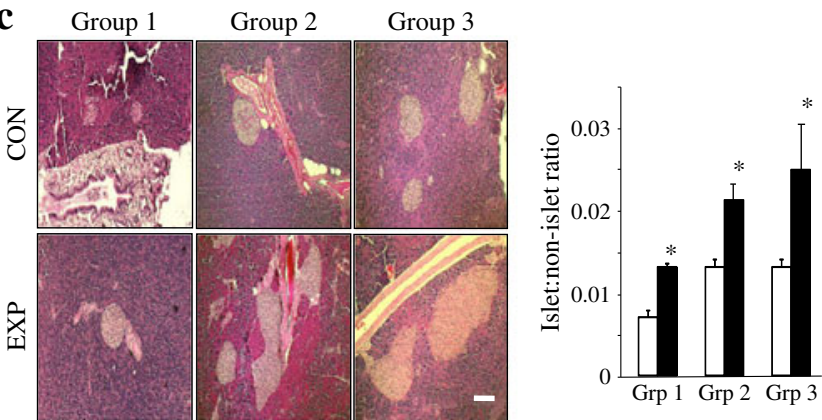

Fig. 3 Deletion of Pten in adult ( $>1$ year old) beta cells leads to expansion of relative islet area. (a) Schematic figure of the experimental protocol. At 12 months of age, mice were treated with tamoxifen $(30 \mathrm{mg})$ or corn oil (vehicle) and then killed for analysis at 1 month (Group 1), 9 months (Group 2) or 12 months (Group 3) after the last injection. Corn oil- and tamoxifen-treated $\mathrm{CreER}^{-}$mice and corn oil-treated $\mathrm{CreER}^{+}$ mice were controls $(\mathrm{CON})$ whereas tamoxifen-treated $\mathrm{CreER}^{+}$mice were experimental (EXP) mice. (b) Immunofluorescent staining of mouse pancreas sections with insulin (green), PTEN (red) and DAPI (DA, blue). PTEN was expressed in the nucleus of the islet cells from CON and was lacking in the EXP islets. Inset, higher magnification images of boxed areas. (c) Representative image of CON and Pten null (EXP) mouse pancreases stained with $\mathrm{H} \& \mathrm{E}$. Islet to non-islet area ratio was analysed and calculated ( $n=3$ or 4 per genotype per group). The error bars represent the SEM for all mice analysed for that group. ${ }^{*} p<0.05, \mathrm{CON}$ (white bars) vs Pten null (EXP, black bars) groups. Scale bars, $50 \mu \mathrm{m}$

is in peri-islets, as reported previously [18], possibly due to infiltrating inflammatory cells. In Group 2 and 3 mice, very little insulin-positive islets remained in CON mice, likely due to the higher susceptibility to STZ treatment and reduced ability to regenerate in older mice $[19,25]$. In these older mice, mitotic activity was also observed in EXP mice whereas little or no mitotic activity was observed in the rare remnant CON islets. We also evaluated cell death in response to Pten deletion in adult islets. In the STZ-treated mice, death of beta cells (TUNEL positive) was observed in both the CON and EXP mice (Fig. 6c) with no difference between the CON and EXP groups in Group 1 mice (approximately $0.54 \pm 0.2 \%$ vs 

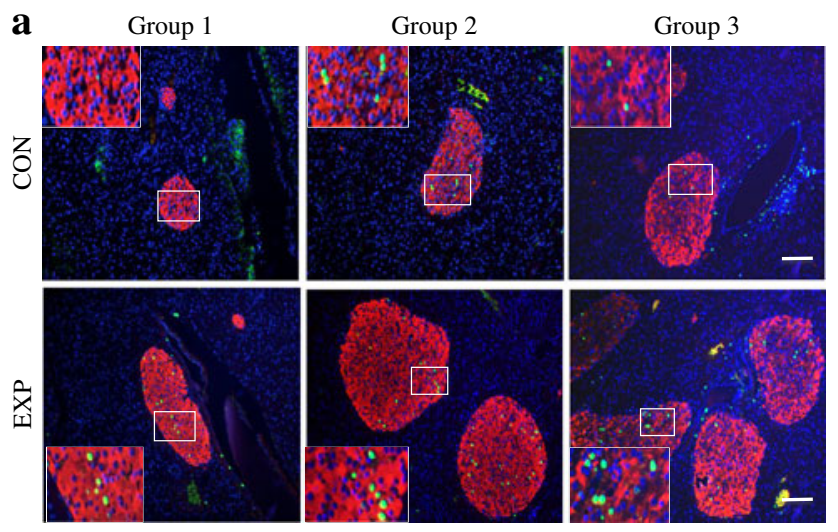

Insulin + BrdU + DAPI

b

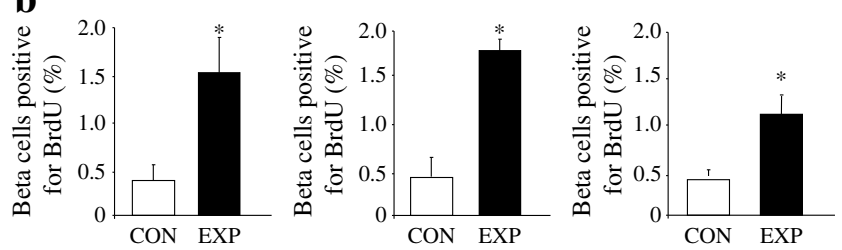

Fig. 4 Deletion of Pten in adult ( $>1$ year) beta cells leads to increased cell proliferation. (a) Pancreases from control (CON) and Pten null (EXP) mice were analysed for insulin (red), BrdU (green) and DAPI (blue) using immunofluorescence. Group 1 was analysed 1 month after the last dose of tamoxifen in 12-month-old mice. Groups 2 and 3 were 9 months and 12 months post treatment, respectively. Inset, higher magnification images of boxed areas. Scale bar, $50 \mu \mathrm{m}$. (b) Quantification of BrdU and insulin double-positive cells. Data are reported as percentage of BrdU + insulin double-positive vs total insulin-positive cells. The bars represent the average percentage of BrdU-positive beta cells in CON and Pten null (EXP) mouse islets. The error bars represent the SEM for all mice analysed for that group ( $n=3$ or 4 per genotype per group). ${ }^{*} p<0.05$, CON vs Pten null (EXP) groups

$0.6 \pm 0.3 \%, n=4$ or 5$)$. There appeared to be fewer cells positive for TUNEL in EXP vs CON mice in Group 2 and 3 mice (ESM Fig. 4). However, since remnant islets do not express insulin, the true identity of the dying cells could not be assessed. Together, these data suggest that inhibition of PTEN function in postnatal islets is capable of inducing proliferation, and may block beta cell death induced by injury, resulting in preservation of the functions of islets. Consistently, insulin levels were also higher in the EXP group $(4.51 \pm 0.49 \mathrm{pmol} / 1$ in EXP vs $3.47 \pm 0.02 \mathrm{pmol} / 1$ in CON for Group 1, $n=3$ ).

Cell-cycle regulation is altered when Pten is deleted in aged beta cells To explore the molecular mechanism for the PTENregulated beta cell proliferation, we investigated the cell-cycle regulatory mechanisms at $\mathrm{G} 1 / \mathrm{S}$ transition. We determined the levels of cyclin D1, cyclin D2 and p27 in 15-month-old mice, 3 months after initial treatment with tamoxifen or vehicle. We found that both cyclin D1 and cyclin D2 levels were induced in islets of the EXP groups in which PTEN is lost vs the controls (CON) with intact PTEN. Concomitantly, induced
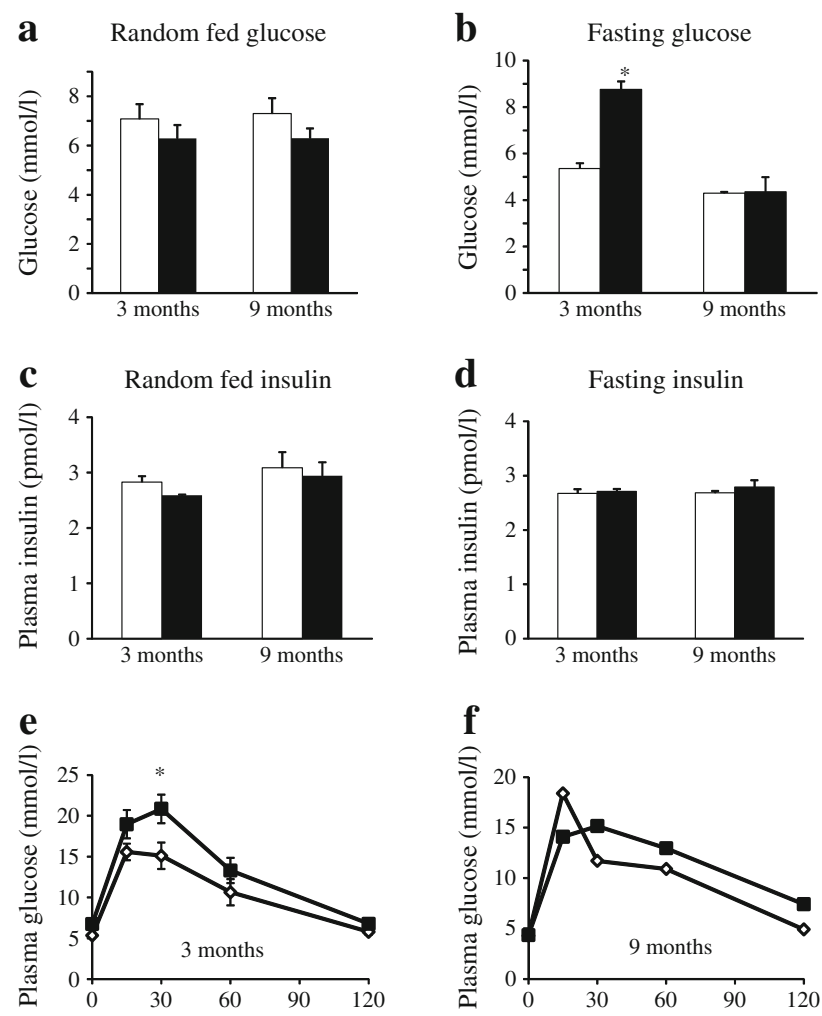

Time after glucose injection( $\mathrm{min}$ )

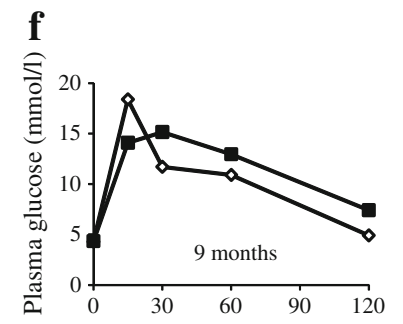

Fig. 5 Deletion of Pten in adult beta cells does not significantly affect glucose and insulin homeostasis. (a-d) Plasma glucose (a, b) and insulin levels $(\mathbf{c}, \mathbf{d})$ were determined from random-fed and fasted mice. White bars, control mice; black bars, experimental mice. (e, f) Glucose tolerance tests were performed in overnight-fasted mice 1 month after the last dose of tamoxifen in 3- and 9-month-old mice. Diamonds, control mice; squares, experimental mice. $n=5$ or 6 per genotype per group; $n=2$ for 9 -month old mice. The error bars represent the SEM for all mice analysed for that group. ${ }^{*} p<0.05$ control vs experimental groups

PTEN loss in these mice led to downregulation of cell-cycle inhibitor p27 (Fig. 7a, c). We further explored the effect of adult-onset of PTEN loss on the EZH2-p16 ${ }^{\mathrm{INK} 4 \mathrm{a}}$ signal complex. Similar to previous observations with Pten ${ }^{\text {loxP/loxP }}$; RIP-Cre ${ }^{+}$mice [19], adult-onset deletion of Pten resulted in upregulation of EZH2 and downregulation of $\mathrm{p} 16^{\mathrm{INK} 4 \mathrm{a}}$ (Fig. 7b, c). Together, these G1/S transition proteins, particularly those involved in regulation of $\mathrm{p} 16^{\mathrm{INK} 4 \mathrm{a}}$, may compose the downstream regulatory network that mediates PTEN/PI3K-regulated beta cell proliferation in adult animals.

\section{Discussion}

During adult maintenance of beta cells, replication of beta cells is the major mechanism that sustains the islet mass while neogenesis may play a role in other circumstances [20, 23, 26]. In murine models, the rate of beta cell mitosis decreases rapidly 2-3 weeks after birth, from approximately $30 \%$ in the 
Fig. 6 Deletion of Pten in adult beta cells prevents STZ-induced loss of islet function. (a) Random plasma glucose levels in STZ-treated control (CON) and Pten null (EXP) mice 10 days after the initial dose of STZ. Group 1 experiments were performed 1 month after the last dose of tamoxifen in 3-month-old mice. Groups 2 and 3 were 3 months and 6 months post treatment, respectively ( $n=4$ or 5 per genotype, per group). ${ }^{*} p<0.05$, CON vs Pten null (EXP) groups. (b) Representative images of BrdU staining. STZ-treated control $(\mathrm{CON})$ and Pten null (EXP) mice were provided $\mathrm{BrdU}$ in drinking water for 5 consecutive days. The sectioned pancreas tissues were analysed for BrdU (green) using immunofluorescence. The tissues were also stained for insulin (red). Inset, higher magnification images of boxed areas. (c) Representative image of TUNEL analysis in Group 1 mice. STZ-treated control (CON) and Pten null (EXP) pancreases were sectioned and analysed for apoptosis using an immunofluorescence TUNEL assay (TUNEL, green; DAPI, blue). Inset, higher magnification images of the boxed areas. Scale bars, $50 \mu \mathrm{m}$
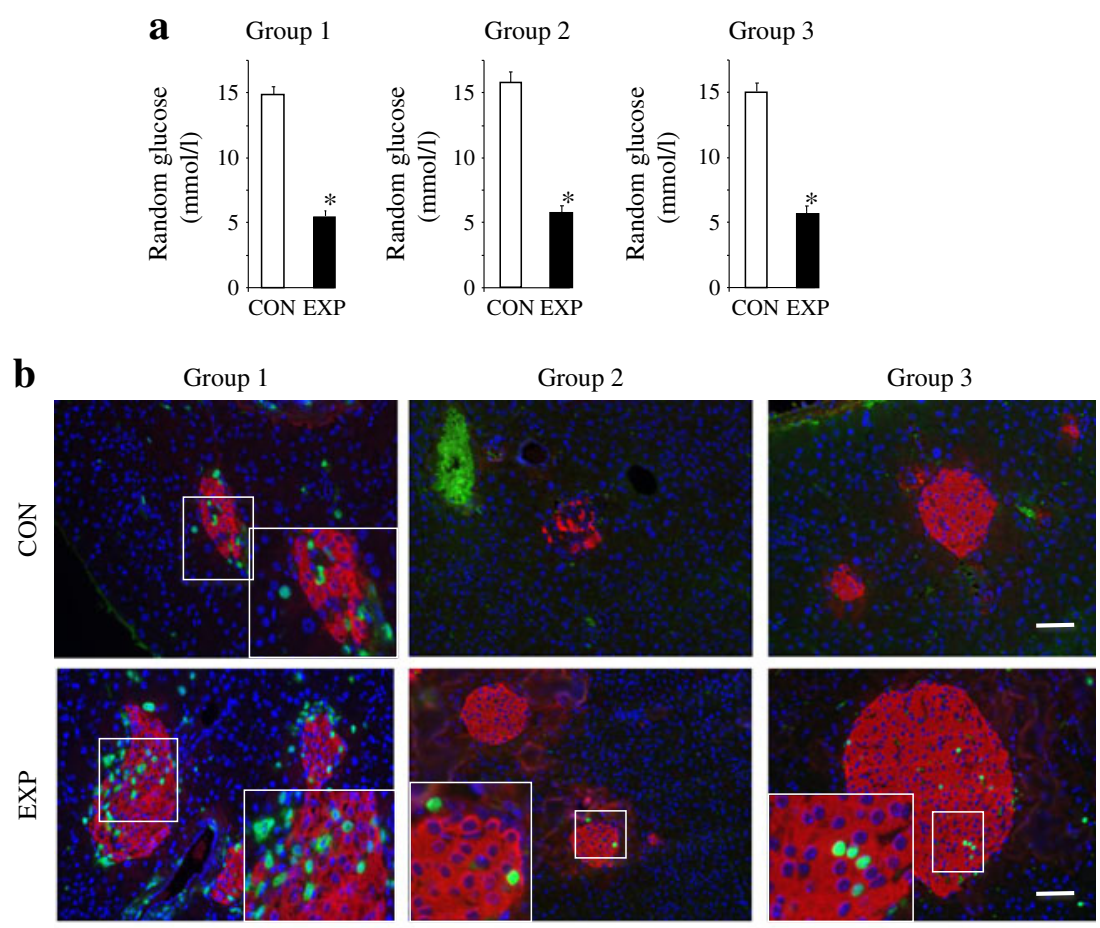

Insulin + BrdU + DAPI
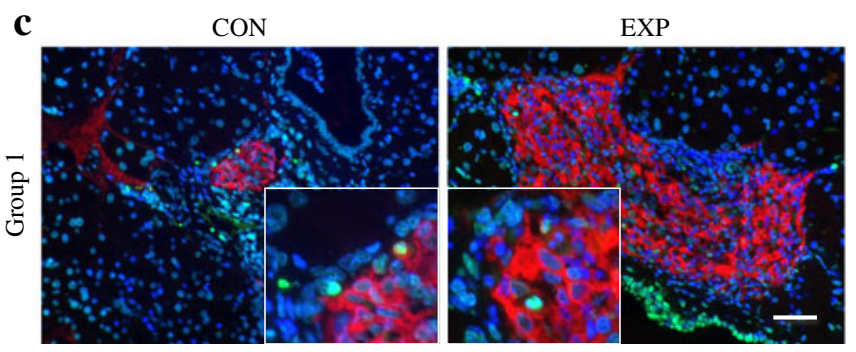

Insulin + TUNEL + DAPI first week after birth to less than $1 \%$ at 2 months of age [2, 19, 27]. Similar observations have been made in the human pancreas where a drop of $1.3 \%$ to $0.08 \%$ mitotic activity was observed between the perinatal stage and 6 months of age [28]. The mitotic activity is then maintained at this low rate unless stimulation occurs, such as obesity, pregnancy or injury [29]. These studies suggest that the proliferation of islet beta cells may be governed by two sets of mechanisms: those that control physiological maintenance of beta cells in adulthood and those controlling the islet beta cell response to stimulation and their growth during early postnatal development. Under STZ-induced injury conditions, we showed previously that loss of PTEN (Pten ${ }^{\text {loxP/loxP }}$; RIP-Cre ${ }^{+}$) and activation of PI3K signalling led to increased proliferation [18]. In high-fat diet-induced obese mice and $d b / d b$ mice, beta cells lacking PTEN (Pten ${ }^{\text {loxP/loxP }}$; RIP-Cre ${ }^{+}$) displayed enhanced ability to respond to hyperglycaemia $[17,30]$. This suggests that PTEN-regulated signals are important for the physiological response of beta cells to hyperglycaemia and injury. Intriguingly, when Pten ${ }^{\text {loxP/loxP }}$; RIP-Cre ${ }^{+}$mice get older, an exponential increase in islet/pancreas ratio is observed, suggesting a role for PTEN and PTEN-regulated signals specifically in aged beta cells [19]. We tested this hypothesis using the novel Pten ${ }^{\text {loxP/loxP }} ;$ Rosa ${ }^{\text {lacZ/lacZ; }}$ RIP-CreER ${ }^{+}$model, in which Pten deletion is induced by injection of tamoxifen. We showed, for the first time, that deletion of Pten and upregulation of PI3K/Akt signal in the beta cells of 3-and 12-month-old mice induces the mitotic activity of the beta cells and increases the islet/pancreas ratio. Furthermore, in mice older than 1 year (when physiological stimulations fail to induce proliferation of beta cells in wild type mice [1]), deletion of Pten was still capable of enhancing proliferation and islet mass. These results suggest that PTEN and pathways regulated by PTEN not only regulate signals that control the response of beta cells to stimulation, but also their maintenance when stimulation signals are no longer present.

The primary consequence of PTEN loss is the activation of $\mathrm{PI} 3 \mathrm{~K} /$ Akt signalling. This is a major mitogenic signalling pathway that controls growth and survival and is regulated by growth factors/hormones including IGF, insulin and HGF. 


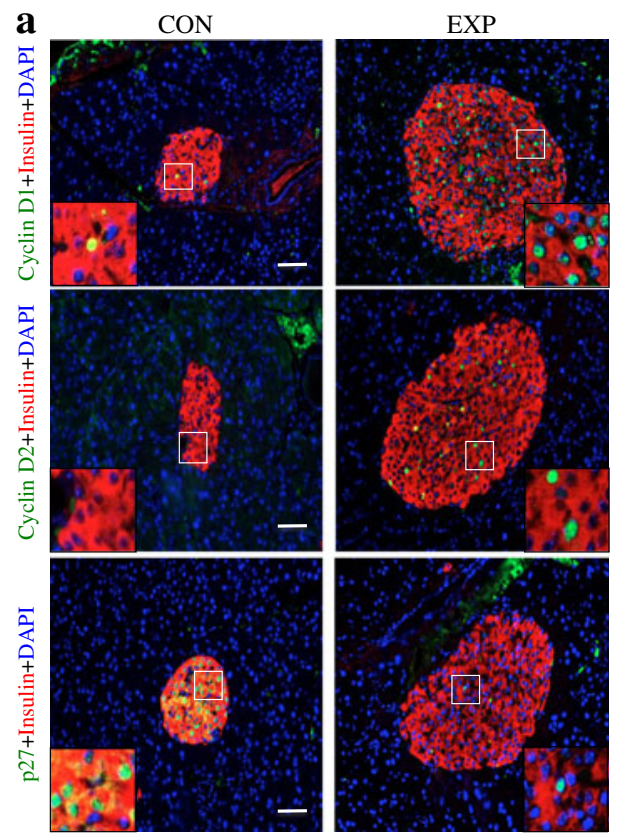

Fig. 7 Deletion of Pten in adult beta cells leads to changes in cell-cycle regulators. (a) Representative image of pancreas from control (CON) and Pten null (EXP) mice. Sections were analysed for insulin (red) and were co-stained for cyclin D1, cyclin D2 or p27 (green) and DAPI (blue) using immunofluorescence. Representative image of five to seven mice.

Manipulation of these growth factor signals has led to alterations in beta cell function [5, 7, 31-35]. Although mice lacking the IGF-1 receptor (or insulin receptor) alone did not display significant abnormality in islet mass, combined deletion of insulin and IGF-1 receptors in beta cells significantly decreased postnatal islet mass [36]. Inactivation of insulin receptor substrate, the target of insulin and IGF-1, also leads to beta cell failure due to decreased proliferation and increased apoptosis [37]. Together, these studies suggest that the IGF-1 signal and its downstream targets, PI3K and Akt, are likely to play important roles in maintaining beta cell functions. Consistently, the overexpression of a constitutively active form of Akt in pancreatic beta cells resulted in an increase in beta cell mass, proliferation, neogenesis and cell size $[13,35]$. Conversely, reducing Akt1 activity by overexpression of a kinasedead mutant in beta cells resulted in glucose intolerance, reduced basal insulin levels and defective insulin secretion [38]. Furthermore, genetic studies of downstream molecules, including mammalian target of rapamycin (mTOR), tuberous sclerosis complex 1/2 (TSC1/2), S6 protein kinase (S6K) and FOXO (forkhead box O protein) [39-44], support a major role for the PI3K signalling pathway in the regulation of beta cell functions. In contrast, PTEN, particularly nuclear PTEN, has been reported to have functions independent of Akt, including an effect on regulating the expression of cyclin D [45]. In the beta cells, PTEN is localised predominantly in the nucleus [24]. Thus, whether the effect of PTEN on adult maintenance of islet mass is mediated by Akt, mitogen-activated protein
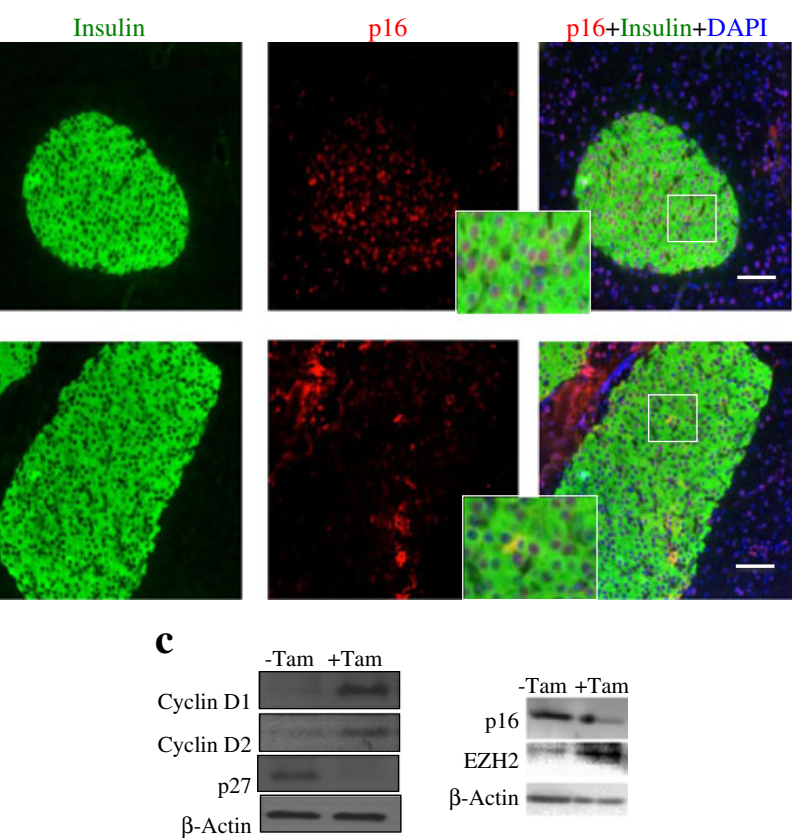

(b) Sections were analysed for insulin (red) and were co-stained for p16 (green) and DAPI (blue) using immunofluorescence. Representative image of two or three mice. (c) Western blot analysis of islet protein lysates isolated from CON and Pten null (EXP) mice. Tam, tamoxifen treatment. Scale bars, $50 \mu \mathrm{m}$

kinase (MAPK) [45], or other unidentified mechanisms, is yet unclear.

The accelerated beta cell proliferation rate observed in the current study is likely to be dependent on the presence of CDK4. We show here that the major partners for CDK4, the D-type cyclins (particularly cyclin D1), are robustly induced when Pten is deleted. Furthermore, p27, an inhibitor for the CDK4/cyclin D complex, is downregulated as a result of PTEN loss. This observation is supported by previous studies showing that global deletion of cyclins D1 and D2 resulted in a decrease in islet mass, beta cell proliferation and glucose tolerance [46]. Conversely, mice lacking p27 displayed increased islet mass and beta cell proliferation and improved glucose tolerance [47]. Concomitant deletion of the pocket proteins controlling G1/S-phase cell-cycle transition, $\mathrm{pRb}$ and p130 also resulted in accelerated beta cell replication, reduced apoptotic cell death and increased beta cell mass [48]. Our results, collected in mice where the Pten gene was manipulated specifically in adult beta cells, are consistent with these cell-cycle studies performed in mice carrying global gene alterations.

Recently, the analysis of PDGF signalling in beta cells revealed that cyclin D1 mediates $\mathrm{p} 16^{\mathrm{INK} 4 \mathrm{a}}$ downregulation [12]. PDGF appears to upregulate cyclin D1 by inducing the phosphorylation and activation of extracellular signalregulated kinase (ERK) signalling. While inhibition of ERK in vitro has not consistently resulted in $\mathrm{p} 16^{\mathrm{INK} 4 \mathrm{a}}$ downregulation, an in vivo study in islets showed that ERK inhibitors are 
capable of blocking PDGF-AA-mediated induction of EZH2 [12]. One of the major consequences of PTEN loss is induction of cyclin D proteins that can occur through both Akt- and MAPK-dependent pathways $[49,50]$. Our recent study shows that the induction of cyclin D1 resulting from PTEN loss probably leads to inhibition of p16 $6^{\text {ink4a }}$ by inducing E2Fs activity and subsequently EZH2 expression [19]. Here, our signalling analysis carried out in 12-month-old mice in which physiological changes (pregnancy, obesity, or injury to beta cells) are unable to stimulate the beta cell regeneration response, confirms that the EZH2-p16 ${ }^{\mathrm{INK} 4 \mathrm{a}}$ signalling node is particularly relevant to PTEN signalling in adult mice. Previous work has established that loss of either EZH2 (or another polycomb protein, polycomb ring finger oncogene [BMI]) can reduce the proliferation capacity of beta cells, resulting in the inability of beta cells to expand their mass in response to injury $[21,22]$. Without the alterations of these polycomb proteins and downregulation of $\mathrm{p} 16^{\mathrm{INK} 4 \mathrm{a}}$, upregulation of the G1/S signal by itself may not be sufficient to overcome the regeneration blockage in adult islets [3, 20]. Manipulation of PTEN and alteration of PTEN-regulated signals appear to be able to alter both the G1/S signalling network and this critical age-regulatory network, resulting in the observed regeneration phenotypes in aged mice.

In summary, our study shows that manipulating PI3K signalling by deleting its negative regulator PTEN significantly induces the proliferation capacity of adult beta cells in young adult mice as well as in mice of advanced age. This data suggests that activation of PI3K signalling (or inhibition of PTEN function) may overcome the inability of aged beta cells to proliferate in response to physiological stimulation. This signalling pathway is likely to control the molecular signals that regulate the age-onset proliferation decay of beta cells.

Acknowledgements We acknowledge the editorial help of B. W. Stiles, Jet Propulsion Laboratory, Pasadena, CA.

Funding J-AB acknowledges support from NIH R36 minority student funding (R36 MD005009-01); NZ acknowledges funding from CBM graduate student training grant; $\mathrm{VM}$ and $\mathrm{AK}$ acknowledge funding from CIRM postdoctoral and graduate student fellowship; BLS acknowledges funding from NIH (NIDDK R21 DK075928-02S1 and R01 DK084241-01A1).

Duality of interest The authors declare that there is no duality of interest associated with this manuscript.

Contribution statement All authors contributed to experimental designs, data analysis, performing experiments, writing and revising the manuscript. The submitted version of the manuscript was approved by all authors.

\section{References}

1. Rankin MM, Kushner JA (2009) Adaptive beta-cell proliferation is severely restricted with advanced age. Diabetes 58:1365-1372
2. Teta M, Long SY, Wartschow LM, Rankin MM, Kushner JA (2005) Very slow turnover of beta-cells in aged adult mice. Diabetes 54: 2557-2567

3. Tschen SI, Dhawan S, Gurlo T, Bhushan A (2009) Age-dependent decline in beta-cell proliferation restricts the capacity of beta-cell regeneration in mice. Diabetes 58:1312-1320

4. Perl S, Kushner JA, Buchholz BA et al (2010) Significant human beta-cell turnover is limited to the first three decades of life as determined by in vivo thymidine analog incorporation and radiocarbon dating. J Clin Endocrinol Metab 95:E234-E239

5. Dai C, Huh CG, Thorgeirsson SS, Liu Y (2005) Beta-cell-specific ablation of the hepatocyte growth factor receptor results in reduced islet size, impaired insulin secretion, and glucose intolerance. Am J Pathol 167:429-436

6. Mellado-Gil J, Rosa TC, Demirci C et al (2011) Disruption of hepatocyte growth factor/c-Met signaling enhances pancreatic betacell death and accelerates the onset of diabetes. Diabetes 60:525-536

7. Garcia-Ocana A, Takane KK, Syed MA, Philbrick WM, Vasavada RC, Stewart AF (2000) Hepatocyte growth factor overexpression in the islet of transgenic mice increases beta cell proliferation, enhances islet mass, and induces mild hypoglycemia. J Biol Chem 275:1226-1232

8. Vila MR, Nakamura T, Real FX (1995) Hepatocyte growth factor is a potent mitogen for normal human pancreas cells in vitro. Lab Invest 73:409-418

9. Agudo J, Ayuso E, Jimenez Vet al (2008) IGF-I mediates regeneration of endocrine pancreas by increasing beta cell replication through cell cycle protein modulation in mice. Diabetologia 51:1862-1872

10. George M, Ayuso E, Casellas A, Costa C, Devedjian JC, Bosch F (2002) Beta cell expression of IGF-I leads to recovery from type 1 diabetes. J Clin Invest 109:1153-1163

11. Robertson K, Lu Y, de Jesus K et al (2008) A general and islet cellenriched overexpression of IGF-I results in normal islet cell growth, hypoglycemia, and significant resistance to experimental diabetes. Am J Physiol Endocrinol Metab 294:E928-E938

12. Chen H, Gu X, Liu Y et al (2011) PDGF signalling controls agedependent proliferation in pancreatic beta-cells. Nature 478:349-355

13. Bernal-Mizrachi E, Wen W, Stahlhut S, Welling CM, Permutt MA (2001) Islet beta cell expression of constitutively active Akt1/PKB alpha induces striking hypertrophy, hyperplasia, and hyperinsulinemia. J Clin Invest 108:1631-1638

14. Cho H, Thorvaldsen JL, Chu Q, Feng F, Birnbaum MJ (2001) Akt1/PKBalpha is required for normal growth but dispensable for maintenance of glucose homeostasis in mice. J Biol Chem 276:38349-38352

15. Liu W, Chin-Chance C, Lee EJ, Lowe WL Jr (2002) Activation of phosphatidylinositol 3-kinase contributes to insulin-like growth factor I-mediated inhibition of pancreatic beta-cell death. Endocrinology 143:3802-3812

16. Kushner JA, Simpson L, Wartschow LM et al (2005) Phosphatase and tensin homolog regulation of islet growth and glucose homeostasis. J Biol Chem 280:39388-39393

17. Nguyen KT, Tajmir P, Lin CH et al (2006) Essential role of Pten in body size determination and pancreatic beta-cell homeostasis in vivo. Mol Cell Biol 26:4511-4518

18. Stiles BL, Kuralwalla-Martinez C, Guo W et al (2006) Selective deletion of Pten in pancreatic beta cells leads to increased islet mass and resistance to STZ-induced diabetes. Mol Cell Biol 26:2772-2781

19. Zeng N, Yang KT, Bayan JA, et al (2013) PTEN controls $\beta$-cell regeneration in aged mice by regulating cell cycle inhibitor p16ink4a. Aging Cell. doi:10.1111/acel.12132

20. Teta M, Rankin MM, Long SY, Stein GM, Kushner JA (2007) Growth and regeneration of adult beta cells does not involve specialized progenitors. Dev Cell 12:817-826

21. Chen H, Gu X, Su IH et al (2009) Polycomb protein Ezh2 regulates pancreatic beta-cell Ink4a/Arf expression and regeneration in diabetes mellitus. Genes Dev 23:975-985 
22. Dhawan S, Tschen SI, Bhushan A (2009) Bmi-1 regulates the Ink4a/ Arf locus to control pancreatic beta-cell proliferation. Genes Dev 23: 906-911

23. Dor Y, Brown J, Martinez OI, Melton DA (2004) Adult pancreatic beta-cells are formed by self-duplication rather than stem-cell differentiation. Nature 429:41-46

24. Perren A, Komminoth P, Saremaslani P et al (2000) Mutation and expression analyses reveal differential subcellular compartmentalization of PTEN in endocrine pancreatic tumors compared to normal islet cells. Am J Pathol 157:1097-1103

25. Hartmann K, Besch W, Zuhlke H (1989) Spontaneous recovery of streptozotocin diabetes in mice. Exp Clin Endocrinol 93:225-230

26. Georgia S, Bhushan A (2004) Beta cell replication is the primary mechanism for maintaining postnatal beta cell mass. J Clin Invest 114:963-968

27. Finegood DT, Scaglia L, Bonner-Weir S (1995) Dynamics of betacell mass in the growing rat pancreas. Estimation with a simple mathematical model. Diabetes 44:249-256

28. Kassem SA, Ariel I, Thornton PS, Scheimberg I, Glaser B (2000) Beta-cell proliferation and apoptosis in the developing normal human pancreas and in hyperinsulinism of infancy. Diabetes 49:1325-1333

29. Bernard-Kargar C, Ktorza A (2001) Endocrine pancreas plasticity under physiological and pathological conditions. Diabetes 50(suppl 1):S30 S35

30. Wang L, Liu Y, Yan Lu S et al (2010) Deletion of Pten in pancreatic ss-cells protects against deficient ss-cell mass and function in mouse models of type 2 diabetes. Diabetes 59:3117-3126

31. Garcia-Ocana A, Vasavada RC, Cebrian A et al (2001) Transgenic overexpression of hepatocyte growth factor in the beta-cell markedly improves islet function and islet transplant outcomes in mice. Diabetes 50:2752-2762

32. Kulkarni RN, Holzenberger M, Shih DQ et al (2002) beta-cell-specific deletion of the Igfl receptor leads to hyperinsulinemia and glucose intolerance but does not alter beta-cell mass. Nat Genet 31:111-115

33. Lu Y, Herrera PL, Guo Y et al (2004) Pancreatic-specific inactivation of IGF-I gene causes enlarged pancreatic islets and significant resistance to diabetes. Diabetes 53:3131-3141

34. Okada T, Liew CW, Hu J et al (2007) Insulin receptors in beta-cells are critical for islet compensatory growth response to insulin resistance. Proc Natl Acad Sci U S A 104:8977-8982

35. Tuttle RL, Gill NS, Pugh W et al (2001) Regulation of pancreatic beta-cell growth and survival by the serine/threonine protein kinase Akt1/PKBalpha. Nat Med 7:1133-1137

36. Ueki K, Okada T, Hu J et al (2006) Total insulin and IGF-I resistance in pancreatic beta cells causes overt diabetes. Nat Genet 38:583-588
37. Kubota N, Tobe K, Terauchi Y et al (2000) Disruption of insulin receptor substrate 2 causes type 2 diabetes because of liver insulin resistance and lack of compensatory beta-cell hyperplasia. Diabetes 49:1880-1889

38. Bernal-Mizrachi E, Fatrai S, Johnson JD et al (2004) Defective insulin secretion and increased susceptibility to experimental diabetes are induced by reduced Akt activity in pancreatic islet beta cells. J Clin Invest 114:928-936

39. Balcazar N, Sathyamurthy A, Elghazi L et al (2009) mTORC1 activation regulates beta-cell mass and proliferation by modulation of cyclin D2 synthesis and stability. J Biol Chem 284:7832-7842

40. Buteau J, Accili D (2007) Regulation of pancreatic beta-cell function by the forkhead protein FoxO1. Diabetes Obes Metab 9(suppl 2): 140-146

41. Buteau J, Shlien A, Foisy S, Accili D (2007) Metabolic diapause in pancreatic beta-cells expressing a gain-of-function mutant of the forkhead protein Foxo1. J Biol Chem 282:287-293

42. Pende M, Kozma SC, Jaquet M et al (2000) Hypoinsulinaemia, glucose intolerance and diminished beta-cell size in S6K1-deficient mice. Nature 408:994-997

43. Rachdi L, Balcazar N, Osorio-Duque F et al (2008) Disruption of Tsc2 in pancreatic beta cells induces beta cell mass expansion and improved glucose tolerance in a TORC1-dependent manner. Proc Natl Acad Sci U S A 105:9250-9255

44. Shigeyama Y, Kobayashi T, Kido Y et al (2008) Biphasic response of pancreatic beta-cell mass to ablation of tuberous sclerosis complex 2 in mice. Mol Cell Biol 28:2971-2979

45. Planchon SM, Waite KA, Eng C (2008) The nuclear affairs of PTEN. J Cell Sci 121:249-253

46. Kushner JA, Ciemerych MA, Sicinska E et al (2005) Cyclins D2 and D1 are essential for postnatal pancreatic beta-cell growth. Mol Cell Biol 25:3752-3762

47. Rachdi L, Balcazar N, Elghazi L et al (2006) Differential effects of p27 in regulation of beta-cell mass during development, neonatal period, and adult life. Diabetes 55:3520-3528

48. Harb G, Vasavada RC, Cobrinik D, Stewart AF (2009) The retinoblastoma protein and its homolog p130 regulate the G1/S transition in pancreatic beta-cells. Diabetes 58:1852-1862

49. Chung JH, Eng C (2005) Nuclear-cytoplasmic partitioning of phosphatase and tensin homologue deleted on chromosome 10 (PTEN) differentially regulates the cell cycle and apoptosis. Cancer Res 65: 8096-8100

50. Radu A, Neubauer V, Akagi T, Hanafusa H, Georgescu MM (2003) PTEN induces cell cycle arrest by decreasing the level and nuclear localization of cyclin D1. Mol Cell Biol 23:6139-6149 